\title{
The problem of self-perception in gifted children in the context of psychology of sustainable development
}

\author{
Elena Belova* \\ Psychological Institute of the Russian Academy of Education, 125009 Moscow, Russia
}

\begin{abstract}
The study of the sphere of self-awareness of a developing personality is one of the urgent tasks of the psychology of sustainable development. The article deals with the problem of self-perception of children in connection with the problem of giftedness. High creativity is understood as the basis of giftedness. The main attention is paid to preschool age as an important initial period in the formation of personality and the development of the abilities and talents of children. The results of an empirical study of the specificity of self-perception in children of 6-7 years old with signs of giftedness in comparison with their peers are presented. The features of the profiles "I-real" and "I-ideal" in preschoolers are described, taking into account the creative potential, gender. It is emphasized that the educational environment at the stage of preschool childhood should be built taking into account the development trends of modern children: understanding the specifics of not only the cognitive, but also the personal sphere of their development.
\end{abstract}

\section{Introduction}

Solving the problems of sustainable social and economic development of the country and the planet as a whole makes it necessary to educate the younger generation capable of acting and living in rapidly changing conditions: to participate in planning social development, to learn to foresee the consequences of the actions taken, including possible consequences in the field of the sustainability of natural ecosystems and social structures. In this regard, the requirements for the education system are increasing. A general, global trend in the development of education is becoming a priority, according to which competence and, accordingly, the personality of the student come to the fore for the purpose of learning. As V.I.Panov notes, the requirement for environmental friendliness of educational technologies and educational environment in the sense of their compliance with natural physiological and psychological, as well as social characteristics and patterns of development of students is becoming more and more urgent [1]. At the present stage of development of society, the main tasks of education include the creation of an educational environment of a developing (creative) type, i.e. environment, providing an opportunity for the manifestation and development of potential abilities of students [1,2].

\footnotetext{
*Corresponding author: elenasbelova@ mail.ru
} 
The idea of correlating the main structural elements that characterize creativity and creative development of a person with the psychological structure of giftedness was fundamental in the concept of "Creative giftedness" by A.M. Matyushkin [3]. Giftedness was considered by scientists as a prerequisite for the formation and development of a creative personality. Education and development of gifted and talented children, according to A.M. Matyushkin, can constitute an ideal model of human creative development. Giftedness is based on creativity, which may differ from person to person, the gifted have a high creative potential, the dominant cognitive motivation is expressed in the form of research, search activity. Emphasizing the importance of the integral approach in the research of giftedness, A.M. Matyushkin noted that the core of the development of giftedness is the need-emotional, volitional and intellectual spheres [3].

The evaluative function of all complex psychological structures was distinguished by A.M. Matyushkin as an integral structural component of giftedness. The scientist wrote that "the ability to assess provides opportunities for self-sufficiency, self-control, confidence of a gifted, creative child in himself, in his abilities, in his decisions, thereby determining his independence, non-conformity and many other intellectual and personal qualities" [3].

A noticeable general trend in modern psychology of giftedness, notes E.I. Shcheblanova, is the growing recognition of the importance of non-cognitive personal (motivational, emotional, volitional and other) components and their interaction with cognitive abilities in the manifestation and development of giftedness [4]. One of the key components of giftedness in many influential theories in the world is the system of ideas of an extraordinary person about himself (I-concept). However, the question of the specificity and role of these ideas in the development of giftedness at different age stages are still debatable [4-6]. This especially applies to preschool age, when all the basic mental functions and personality traits are formed.

The study was aimed at identifying the characteristics of self-awareness as the main component of the forming personality of a gifted child of 6-7 years old.

The basic ones for the research were: the concept of "Creative giftedness" by A.M. Matyushkin [3]. The research tasks included:

- identification of gifted 6-7-year-old children with high creative potential;

- analysis of the characteristics of their self-perception and self-acceptance in comparison with their peers, whose creative potential was less pronounced;

- identification of gender characteristics of self-perception of gifted children.

\section{Materials and methods}

The study involved 150 preschoolers 6-7 years old, who attended preparatory groups of kindergartens in Moscow. The number of girls and boys was approximately equal.

The diagnostic complex of techniques included: identification of the level of creative potential: Torrance Tests of Creative Thinking (TTCT form A), adapted for preschoolers by E.S. Belova and E.I. Shcheblanova; analysis of the products of children's creative activity (drawings, crafts, etc.); observation of preschoolers in the classroom and in the conditions of free games; a survey of parents and teachers about the peculiarities of the individual development of children using special questionnaires; study of the child's ideas about himself and the subjective ideal, the peculiarities of self-acceptance, the "Portraits" method was used in the modification of O.A. Belobrykina, N.Y. Bolshunova [7]; methods of mathematical statistics (statistical package SPSS Statistics 22.0). 


\section{Results}

In accordance with the objectives of the study, among all surveyed preschoolers, two groups of children, equal in number, differing in their level of creative potential, were identified. Group I consisted of preschoolers with high creative potential (the values of the total T-indicator according to the Torrance Tests were equal to or exceeded 60 points) gifted children $(\mathrm{N}=22)$, group II included preschoolers whose creative abilities were less expressed, the level of creativity was medium or low (the values of the total T-score according to the Torrance Tests were equal to or below 50 points). When forming group II, to ensure representativeness, a random strategy was also used as a technique. The conducted comparative analysis confirmed that the difference between the selected groups according to the Torrance Tests is highly significant ( $p=0.000$ according to the MannWhitney test).

Each preschooler from two groups was presented with a set of ten cards - graphic images of qualities: brave, strong, polite, hardworking, neat, smart, not greedy, does not fight, tells the truth, knows how to play well (the set is differentiated by gender: cards for a boy and for girl). The cards were presented one at a time for familiarization, clarification and consolidation of the designations. Then the child was asked to make a "portrait" of the best child with the help of cards, choosing from the qualities those that, in his opinion, are found most often in the best child, then less often, and so on. (After each card selection, the remaining ones were shuffled). Then the preschooler was asked to compose his own "portrait". The results of the choice of cards were recorded, and then formed the basis for the profile of the child's subjective ideal - "I am ideal" and the profile of the image of oneself - "I am real".

As a result of the elections, in the first place in the "portrait" of the best child among preschoolers from group I, the following qualities stood out: "polite" (27\% of children), "speaks the truth" (27\%), "hardworking" (14\%), "strong " (fourteen\%). Among the first answers about the best child among children of group II, the following qualities stood out: "speaks the truth" (27\%), "polite" (23\%), "strong" (14\%), "courageous" (14\%). When describing themselves, the first names in group I were more often called: "polite" $(18 \%)$, "strong" (18\% of children), "speaks the truth" $(14 \%)$; in group II: "speaks the truth" $(27 \%)$, "strong" (18\% of children) "courageous" (14\%).

Comparative analysis of the "I-ideal" profiles in the two groups showed that the found intergroup differences did not reach the level of significance, individual differences were more pronounced. Comparison of the "I-real" profiles in the groups revealed a difference in the "non-greedy" characteristic: in the gifted group, she was more likely to receive a higher rank than in the peer group ( $\mathrm{p}=0.045$ according to the Mann-Whitney test).

The choices of the first three qualities by preschoolers as the most significant were considered in more detail. Significant differences between the groups (according to the Fisher's criterion) were established in relation to the choice of one of the first three characteristics of the best child by preschoolers: "does not fight" - in the gifted group it was distinguished by a greater number of children than in the peer group $(p=0.007)$; "Brave" in the peer group she was distinguished by a greater number of children than in the gifted group $(p=0.027)$. The difference at the level of the tendency $(p=0.086)$ was found in relation to the characteristic "smart": gifted preschoolers more often singled it out among the first three when drawing up a "portrait" of the best child. When comparing the first three qualities in self-descriptions of preschoolers, intergroup differences at the level of tendencies were revealed in relation to characteristics: "non-greedy" - was more often noted in the group of gifted children $(\mathrm{p}=0.071)$; "Brave" - more often stood out in the group of their peers $(\mathrm{p}=0.062)$. 
To identify the features of self-acceptance, the analysis of the correspondence of the portrait of the "real self" to the subjective ideal of the child was carried out, and the Spearman's rank correlation method was used. As a result, it was found that among preschoolers with adequate self-acceptance, $72.8 \%$ of children in group I and $63.6 \%$ of children in group II. Among preschoolers with an unrealistic level of self-acceptance, an overestimated (idealized) level was found in $13.6 \%$ of children in group I and $27.3 \%$ of children in group II. An underestimated (overly critical) level of self-acceptance was found in $13.6 \%$ of children in group I and $9.1 \%$ in group II. The unrealistic level of selfacceptance found in some children may be associated with insufficient provision of adequate conditions for the educational environment for the development of the child's selfesteem.

A comparative analysis of self-descriptions of gifted boys and self-descriptions of gifted girls showed the following: the characteristic "speaks the truth" in the group of gifted girls has a higher rank than in the group of gifted boys $(p=0.011)$. When comparing the portraits of the best child, it was found that the characteristic "strong" has a higher rank in gifted boys $(p=0.036)$, and the characteristic "neat" has a higher rank in the group of gifted girls $(p=0.063$, tendency level). In terms of creative potential, no differences were found: the level of creative thinking was high both among girls and boys who were part of the gifted group.

\section{Discussion}

In the context of a global deterioration of the ecological and social situation on the planet, a pandemic, a wide digitalization of life and other environmental challenges, the active participation of psychologists is required in ensuring the environmentally friendly existence and development of children and adults in accordance with the goals of the Concept of Sustainable Development of Humanity and the Planet [8]. The process of forming a creative personality, starting from an early age, requires special attention.

Several studies have shown that the majority of gifted children demonstrate higher positive overall, and especially academic self-concept, respectively, their area of giftedness. At the same time, the relationship between giftedness and self-concept can vary depending on age, gender, levels of exclusivity (abilities, giftedness) and real achievements [4-6].

Let us emphasize that research is mainly conducted on school-age children, most often adolescents and youth. The specificity of preschool age in the development of the personal aspects of giftedness is much less often the subject of study. And even the few data found in the literature on the emotional and personal characteristics of gifted children are often ambiguous. Some researchers express an opinion about the increased sensitivity, vulnerability of extraordinary children, their emotional instability, and increased anxiety. Others describe examples of gifted children as emotionally stable, strong-willed, selfconfident children. The facts of discrepancy in the development of intelligence, creativity and emotional-personal sphere of an extraordinary preschooler are presented $[9,10]$.

It should be noted that in Russian psychology, many studies have been devoted to the issues of personal development of preschoolers, and in particular to the development of their self-awareness (L.S. Vygotsky, L.I. Bozhovich, A.V. Zaporozhets, D.B. Elkonin, etc.), and although the problematics of giftedness were not considered in them, a number of important points for its study can be distinguished: self-awareness is considered as one of the leading elements of the mental appearance of a person; in the early stages of personality ontogenesis, self-awareness appears as a dynamic and relatively plastic psychological phenomenon, includes cognitive (self-knowledge is an image of qualities, abilities, skills, etc.), emotional (emotional reactions and judgments), volitional (self-regulation process) 
components; is formed on the basis of the experience of various activities, communication with adults and peers.

In the process of development of a preschooler, the system genesis of the factors that determine the development of the components of self-awareness changes. If at 4-4.5 years old a child's self-esteem is mainly determined by the success of objective activity, then from 4.5-5.5 years old, peer assessments and experience of relationships with them in objective activity begin to exert an increasing influence, and by the age of 7 years the child's communication sphere with peers and adults directly determines the child's attitude to himself and his self-esteem [11].

By the end of preschool age, differentiated self-esteem, self-criticism develops, awareness of oneself appears in time, "personal consciousness" arises (D.B. Elkonin), causing a new level of awareness by the preschooler of his place in the system of relationships with an adult. A preschooler's awareness of his own individual qualities, experiences, his individual significance contributes to a change in the main contradictions of mental development: the contradiction between the "preschool" way of life and the new possibilities of the child appears and becomes more and more pronounced. The specificity of the preschool period revealed in the studies of preschoolers in personal development can be manifested in its own way in gifted children. This was found in our study too: in the profiles compiled according to the descriptions of themselves and the best child by preschoolers with different levels of creativity. In our study, the analysis of the "I-real" profiles in the groups revealed a difference in the characteristic "non-greedy": it was more pronounced in gifted children. The compiled profiles "I-ideal" testified to large individual differences, overlapping intergroup differences.

The educational environment reflects the explicit and implicit values, stereotypes, orientations accepted in society. This also applies to the problems of gifted girls and boys. As a result of sometimes almost imperceptible and seemingly insignificant differences in interaction with parents, teachers and peers, gifted girls, as L.V. Popova notes, acquire some specific features. Many of them deny their talent, explaining their success by external conditions and hard work. The inner barriers of gifted boys are defined by the common image of the "real" man so popular in movies and TV shows. Differences are constructed throughout childhood, adolescence, and this is also reflected in the development of the gifted [12].

Taking into account the relevance of the issues of gender differences, a comparative analysis of self-descriptions of gifted boys and self-descriptions of gifted girls was carried out. It was revealed that in the absence of significant differences in creative potential, there are differences in the perception of some personal characteristics: "speaks the truth" is more expressed in the self-descriptions of girls, "strong" - in the portrait of the best child according to the descriptions of boys.

\section{Conclusions}

The data obtained in the study expands the scientific understanding of the specifics of the process of the formation of the sphere of self-awareness in children with signs of giftedness at the stage of preschool age. The features of their ideas about themselves and the best child are revealed. The compiled profiles "I-real", "I-ideal" reflect the development of selfesteem and characterize the value orientations of personal development.

A gifted child's awareness of his skills, qualities, experiences can be the basis for the formation of an individual intellectual and spiritual and moral resource of a growing personality, capable of further realizing the goals of sustainable innovative development of the country and the world as a whole. 
The educational environment at the stage of preschool childhood should be built taking into account the development trends of modern gifted children, understanding the specifics of not only the cognitive sphere of their development, but also, which is extremely important, the characteristics of personality formation.

\section{References}

1. V.I. Panov, Social psychology and society, 3, 13 (2013)

2. V.I. Panov, Ecopsychology: Paradigmal search, 304 (Moscow, St.Petersburg: Psychological institute of the RAE, Nestor-Istoriya, 2014)

3. A. Matyushkin, European Journal of High Ability, 1(0), 72(1990)

4. E. Shcheblanova, Procedia - Social and Behavioral Sciences, 82, 627 (2019)

5. E.I. Shcheblanova, S.O. Petrova, Psikhologicheskie Issledovaniya, 7 (38), 7 (2014)

6. The Social and Emotional Development of Gifted Children: What Do We Know?(Austin: Prufrock Press, 2015)

7. O.A. Belobrykina, Diagnostics of the development of self-awareness in childhood, (St. Petersburg: Rech, 2006)

8. D.S. Ermakov, V.I. Panov, Psychological Journal, 41 (4), 121 (2020)

9. B. Clark, Growing up Gifted: Developing the Potential of Children at Home and at School (8th ed.), (Upper Saddle River, NJ: Pearson Education, 2013)

10. M. Sutherland, Gifted and Talented in the Early Years: Practical Activities for Children aged 3 to 6, (London: SAGE Publications Ltd, 2012)

11. G. Uruntaeva, Child psychology, (Moscow: INFRA-M, 2020)

12. L.V. Popova, Gender aspects of identifying, developing and realizing giftedness. (Moscow, St.Petersburg: Nestor-Istoriya, 2017) 